\title{
Cardiac Ventricle Laceration in a Battered Child: A Case Report
}

\author{
Pawan Kumar Shukla ${ }^{1}$, Swapan Debbarma ${ }^{2}$, Ashish Ramesh Bhute ${ }^{3}$ \\ ${ }^{1}$ Junior Resident, ${ }^{2}$ Senior Resident, ${ }^{3}$ Assistant Professor, Department of Forensic Medicine \& Toxicology, \\ All India Institute of Medical Sciences (AIIMS), Rishikesh-249203 Uttarakhand, India
}

\begin{abstract}
Cardiac laceration in child abuse cases is uncommon. Very few case studies are available illustrating the left ventricular rupture following blunt chest injuries. This article presents a case of sudden death of a two and a half year-old female child brought with history of fall on level ground while playing. The autopsy revealed multiple types of injuries over the whole body with duration varying from less than a day to more than 6 months old. Left ventricular rupture and liver laceration were the primary injuries contributing to death. Child abuse cases should never be examined with a preconception of finding the classical features of intracranial hematomas.
\end{abstract}

Keywords: Child abuse, left ventricular rupture, heart rupture, cardiac tamponade, autopsy, shaken baby syndrome, blunt cardio-thoracic injury.

\section{Introduction}

Ever since the first case of 'Battered baby syndrome' was described, child abuse cases are increasingly reported in clinical practice. Newer ways of violence against the child are often encountered. The classical description of 'Battered baby syndrome' i.e. due to shaking being the commonest ${ }^{(1,2)}$ to less common causes like beaten to death by parents or caregivers ${ }^{(3)}$, homicidal methanol poisoning ${ }^{(4)}$, homicidal snake bite $^{(5)}$, intestinal perforations ${ }^{(6)}$, hypodermic needle insertion at various body parts of the child ${ }^{(7)}$. Very few articles are available depicting the use of less common method of child exploitation with an unusual outcome. The present case discusses the cardiac complications of blunt thoracoabdominal trauma in a child abuse victim.

\section{Corresponding Author:}

\section{Ashish Ramesh Bhute}

Assistant Professor, Department of Forensic Medicine \& Toxicology, All India Institute of Medical Sciences (AIIMS), Rishikesh-249203 Uttarakhand, India e-mail: ashishbhute@gmail.com

\section{Case Report:}




A two and half year old girl child was brought for autopsy at our institution (Fig.1). History provided by the investigating officer was similar to the history narrated by the mother of child. As per the alleged history, child was playing inside her home along with her two elder brothers, suddenly fell on the ground and became unconscious. The mother tried to wake up the child by shaking off and by splashing water on face but child was unresponsive. Father was a truck driver by profession and was out of station for work. The child was brought to a nearby hospital within 1 hour of the incident. The primary care physician after complete examination declared the child brought dead on arrival. Police were intimated and forensic medicine opinion was sought regarding the case. As per the hospital papers provided with the inquest reports, there was no documentation of attempted cardio-pulmonary resuscitation or any external injury over the exposed parts of the body. Mother gave negative history of any congenital or acquired disease or previous hospitalization. But she admitted to history of frequent falls of child while playing sustaining recent swelling over the forehead and few old scratches over the limbs. As per mother, child was playful, social and never had a similar incident in the past.

The sudden death of an apparently healthy, playful child within 1 hour of incident and negative history of any disease was sufficient for suspicion of child abuse. An autopsy was performed including external examination, internal examination, toxicological analysis of blood and full-body x-ray.

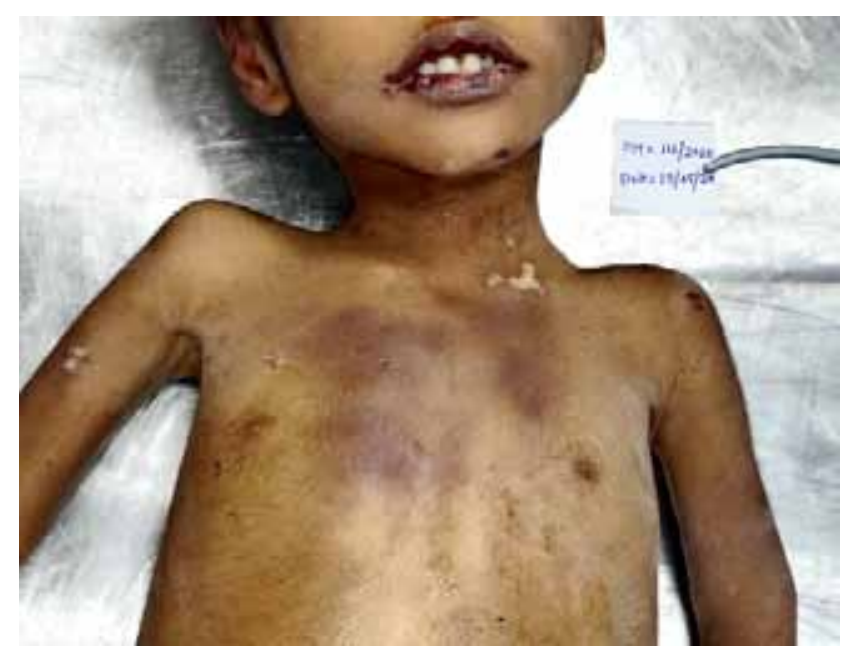

External examination revealed sunken eyes, prominent bony margins, loss of subcutaneous fat and improper pigmentation. There were a total of 43 injuries over the front and back of the body which was of different types, sizes and ages. Out of all, 18 injuries were under 12 hours of duration prior to death and included bruises over the forehead, chest, back, and laceration on the inner surface of the lower lip. Multiple, comparatively large, bruises were present over the sternal area of the chest which were individually and/or collectively responsible for the cause of death (Fig.2). Multiple reddish tram-track bruises were present over the entire back and thighs, suggestive of being caused by a long, slender object.

Six equal-sized circular injuries of duration more than 1-week old were present at different parts of the body, suggestive of being caused by the burning end of cigarette or bidi or with material alike. Few old injuries were also present in the perineal region. The rest of the injuries were old scar marks and their duration varied from 2 weeks to more than 6-month.

Internal examination revealed contusion over the anterior half of the scalp without skull fracture. Thin patches of subarachnoid haemorrhages were present all over the brain. The brain was pale and showing features of oedema. Antemortem fracture of $4^{\text {th }}$ and $5^{\text {th }}$ rib of right side was present $1 \mathrm{~cm}$ lateral to the costochondral junction. Multiple ecchymotic patches were present in the surrounding soft tissues of heart and pleural surface of both lungs. Pericardial cavity contained about $100 \mathrm{ml}$ of liquid and clotted blood (Fig.3a). A 4cm, fullthickness, antemortem lacerated wound was present on the posterior wall of left ventricle (Fig.3b). Ecchymotic patches were present over the anterior surface of heart, root of aorta and near right auricle. Even though the body was emaciated but abdomen was distended. The incision revealed profuse flow of liquid and clotted blood which was approximately $500 \mathrm{ml}$ in volume. The Source of blood was searched for, which revealed contusion over the posterior surface of right lobe of liver along with two lacerations near caudate lobe (Fig.3c). Peri-nephric area of right side was contused along with reduced fat deposit.

Blood sample was collected and sent to forensic science laboratory for toxicological analysis whose report is still awaited, although stomach content did not reveal any unusual finding. X-ray did not show any recent or healing fracture of skull or long bones. 

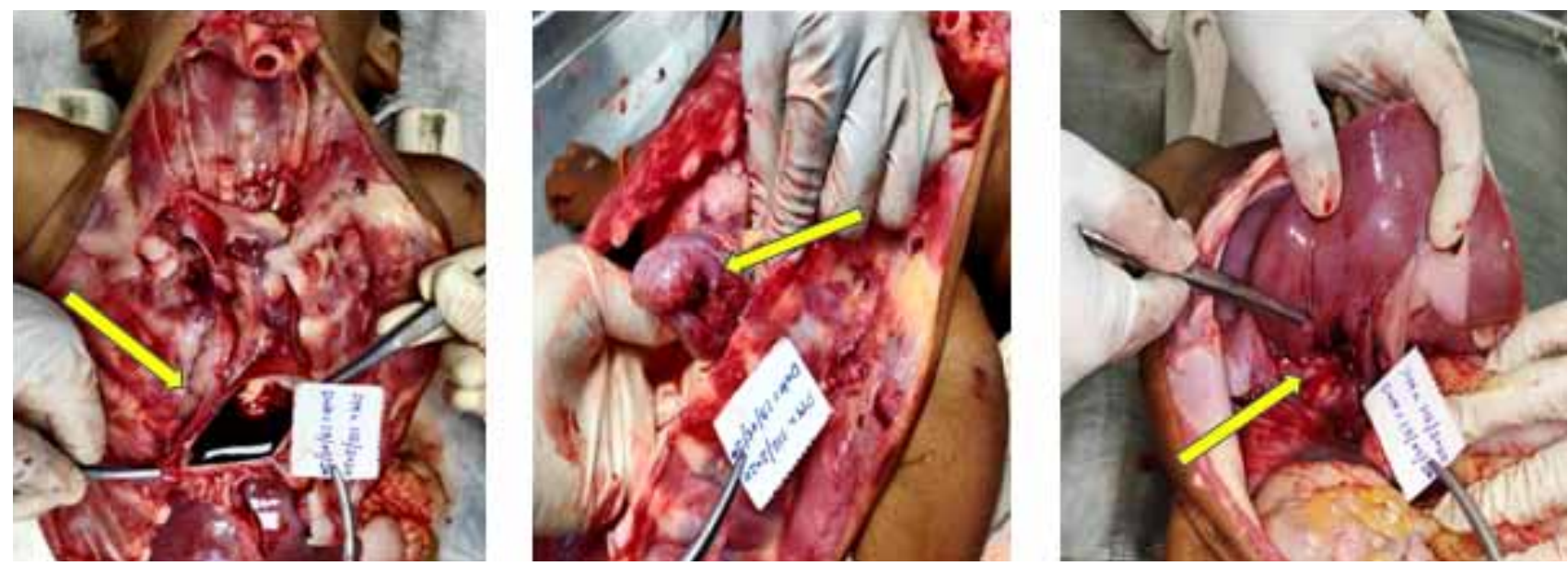

Figure 3: (a) Blood in pericardial cavity, (b) Left ventricle wall rupture, (c) Liver rupture.

\section{Discussion}

In our present case, most of the findings are more in favor of blunt thoracoabdominal trauma. Various literature search guides us that the following cause could be attributed to the death of this child, commotio $\operatorname{cordis}^{(8)}$, right atrium rupture ${ }^{(9)}$, left ventricular rupture $^{(10)}$, traumatic ventricular septal defect ${ }^{(11)}$, traumainduced intra-cardiac thrombus ${ }^{(12)}$ and trauma-induced transection of abdominal aorta or spinal injuries ${ }^{(13)}$.

Since external examination revealed multiple bruises over the sternal area along with fracture of right side ribs and no injuries over the abdomen, death of the child could be ascribed more to chest injury rather than abdominal. Among the above-mentioned causes, right atrial rupture was less likely because the most accepted mechanism causing it is increased hydrostatic pressure subsequent to abdominal trauma. Trauma to abdomen transmits the hydrostatic force to right atrium through inferior vena cava. When the hydrostatic force exceeds the stretchability of right atrium, it results in rupture. However, liver laceration can occur either from a blow over the chest or abdominal ${ }^{(9)}$. Cardiopulmonary resuscitation $(\mathrm{CPR})^{(14)}$ could be a valid reason for bruises over the sternal area. Since the child was brought dead to hospital and hospital records also did not mention any attempt of CPR so this aspect was ruled out. A highquality CPR usually causes fracture of left side ribs but in the present case, ribs were fractured on the right side again disproving the concept of CPR attempt.

Children have a flexible chest wall because of which they are more vulnerable to heart injuries following blunt trauma to the chest. According to a study ${ }^{(15)}$, following blunt cardiac trauma, $87.3 \%$ of the injuries were heart contusion and $10 \%$ accounted for laceration. The present case showed two major injuries left ventricular rupture and liver laceration which was similar to the findings of Cumberland ED et al. ${ }^{(9)}$ and kaptein YE et al. ${ }^{(15)}$.

Cohle $\mathrm{S}$ et al. ${ }^{(16)}$ described six cases of traumainduced cardiac laceration in victims aged between 9 weeks to $2 \frac{1}{2}$ year-old. Right atrium was lacerated in 5 cases and left ventricle in one. Four cases had associated fracture of at least 2 ribs. They proposed the possible causes of cardiac rupture could be a direct blow to the chest, cardiac compression between sternum \& spinal column, blow to the abdominal, deceleration injuries, penetrated cardiac injury by a broken rib and rupture through a previously traumatized heart contusion. They also postulated CPR as the least likely cause of cardiac rupture in children and ruptures acquired at homes, seldom appear to be accidental.

A similar case of child abuse has been reported ${ }^{(10)}$ describing life-threatening left ventricular rupture after blunt chest injury. The autopsy noted multiple bruises all over the body including genitals. Full-thickness laceration was present at the left ventricular apex with $150 \mathrm{ml}$ of blood in the pericardial cavity. Multiple fractures of both sided ribs and laceration of right liver lobe were present. The author opined that the resultant cardiac injury could be due to thoracoabdominal injury. The possibility of abdominal trauma was disregarded because there was no associated injury to inferior vena cava or right side of the heart, caused due to increased hydrostatic 
pressure. The likelihood of thoracic trauma was also less convincing because two contradictory opinions were present regarding the same. A severe blow to the chest during end-diastolic phase of cardiac cycle, when the ventricles are full and atria empty, could cause the rupture of ventricles by raising the hydrostatic pressure to an extreme degree. But at the same time outflow tract of ventricles with one-way valve mechanism also reduces this pressure lowering the chance of tear. Furthermore, the overlying sternal injuries were concomitant or due to previous trauma remained uncertain. Crushing of heart apex between sternum and vertebral column was the best-suited mechanism for ventricle rupture.

Although the mechanism described for left ventricle rupture in the above case was contradictory but it was arguable for our case. In the present case, several findings were appreciable which guided towards a thoracic blow rather than abdominal. Multiple fresh bruises over the sternal area, right side rib fractures, ecchymotic patches over the anterior surface of heart, root of aorta and right auricle, all suggested repeated trauma over the chest simultaneously obstructing the outflow tract of ventricles and intensely increasing the intra-ventricular hydrostatic pressure resulting in rupture of left ventricle and liver. Alternatively, rupture due to compression grinding of the left ventricle between sternum and vertebral column cannot be denied.

\section{Conclusion}

Child abuse cases should never be examined with a preconception of finding the classical features of intracranial hematomas. Cardiac lacerations are the newly described variant of blunt cardio-thoracic injuries in cases of child abuse which are less common than cardiac concussion injuries but nevertheless encountered in clinical practice.

Conflict of Interest: There is no conflict of interest to declare

\section{Source of Funding: None}

\section{References}

1. Saternus K, Kernbach-Wighton G, Oehmichen M. The shaking trauma in infants - kinetic chains. Forensic Sci Int. 2000 Apr 10;109(3):203-13. doi: 10.1016/s0379-0738(00)00144-4. PMID: 10725656.

2. Karibe H, Kameyama M, Hayashi T, Narisawa A,
Tominaga T. Acute Subdural Hematoma in Infants with Abusive Head Trauma: A Literature Review. Neurol Med Chir (Tokyo). 2016 May 15;56(5):26473. doi: 10.2176/nmc.ra.2015-0308. Epub 2016 Mar 10. PMID: 26960448.

3. Cukić D. [Bleeding to death because of hemorrhage into soft tissues as a cause of death in a beaten battered child]. Vojnosanit Pregl. 2011 Dec;68(12):10758. Serbian. doi: 10.2298/vsp1112075c. PMID: 22352272.

4. Beno JM, Hartman R, Wallace C, Nemeth D, LaPoint S. Homicidal methanol poisoning in a child. J Anal Toxicol. 2011 Sep;35(7):524-8. doi: 10.1093/anatox/35.7.524. PMID: 21871164.

5. Paulis MG, Faheem AL. Homicidal Snake Bite in Children. J Forensic Sci. 2016 Mar;61(2):559-561. doi: 10.1111/1556-4029.12997. Epub 2015 Dec 22. PMID: 27404632.

6. Ogata $\mathrm{M}$, Tsuganezawa $\mathrm{O}$. An isolated perforation of the jejunum caused by child abuse. A case report. Am J Forensic Med Pathol. 1995 Mar;16(1):17-20. doi: 10.1097/00000433-199503000-00003. PMID: 7771376.

7. Gupta A, Purbey OP, Sunil K, Pandey A, Kureel SN. Needle Insertion in a Child: A Rare Form of Child Abuse. J Indian Assoc Pediatr Surg. 2018 Jul-Sep;23(3):171-173. doi: 10.4103/jiaps. JIAPS_226_17. PMID: 30050272; PMCID: PMC6042162.

8. Link MS, Wang PJ, Pandian NG, Bharati S, Udelson JE, Lee MY, Vecchiotti MA, VanderBrink BA, Mirra G, Maron BJ, Estes NA 3rd. An experimental model of sudden death due to low-energy chestwall impact (commotio cordis). N Engl J Med. 1998 Jun 18;338(25):1805-11. doi: 10.1056/ NEJM199806183382504. PMID: 9632447.

9. Cumberland GD, Riddick L, McConnell CF. Intimal tears of the right atrium of the heart due to blunt force injuries to the abdomen. Its mechanism and implications. Am J Forensic Med Pathol. 1991 Jun;12(2):102-4. doi: 10.1097/00000433199106000-00003. PMID: 1882772.

10. Yarid N, Brown EC, Boos M, Otjen J, Metz J, Jenny C, Feldman KW. Cardiac Ventricular Laceration Due to Child Abuse: Abusive Ventricular Laceration. J Forensic Sci. 2019 Jan;64(1):284288. doi: 10.1111/1556-4029.13857. Epub 2018 Jul 10. PMID: 29989173. 
11. Rees A, Symons J, Joseph M, Lincoln C. Ventricular septal defect in a battered child. Br Med J. 1975 Jan 4;1(5948):20-1. doi: 10.1136/bmj.1.5948.20. PMID: 1120221.

12. Aşilioğlu N, Paksu MS, Sungur M, Demirel S. Intracardiac thrombus case caused by blunt trauma due to child abuse. Pediatr Emerg Care. 2012 Jun;28(6):566-7. doi: 10.1097/ PEC.0b013e318258bded. PMID: 22668662.

13. Dudley MH, Garg M. Fatal child abuse presenting with multiple vertebral and vascular trauma. J Forensic Sci. 2014 Mar;59(2):386-9. doi: 10.1111/1556-4029.12326. Epub 2014 Feb 27. PMID: 24576044.
14. Olds K, Byard RW, Langlois NE. Injuries associated with resuscitation - An overview. J Forensic Leg Med. 2015 Jul;33:39-43. doi: 10.1016/j.jflm.2015.04.003. Epub 2015 Apr 17. PMID: 26048495.

15. Kaptein YE, Talving P, Konstantinidis A, Lam L, Inaba K, Plurad D, Demetriades D. Epidemiology of pediatric cardiac injuries: a National Trauma Data Bank analysis. JPediatr Surg. 2011 Aug;46(8):156471. doi: 10.1016/j.jpedsurg.2011.02.041. PMID: 21843725.

16. Cohle SD, Hawley DA, Berg KK, Kiesel EL, Pless JE. Homicidal cardiac lacerations in children. J Forensic Sci. 1995 Mar;40(2):212-8. PMID: 7602280 . 